\title{
ANALISIS POLA MIGRASI DAN KONSUMSI RUMAH TANGGA DI DESA PESISIR TERKAIT KEMISKINAN DAN KERENTANAN PANGAN
}

\author{
Armen Zulham ${ }^{1}$, Subhechanis Saptanto',,Retno E. Rahmawati',Lindawati', Teuku Fauzi ${ }^{1}$ \\ ${ }^{1}$ Peneliti pada Balai Besar Riset Sosial Ekonomi Kelautan dan Perikanan \\ JI. KS. Tubun Petamburan VI, Jakarta 10260 \\ Telp. 021 53650162/Fax. 02153650159 \\ ${ }^{2}$ Lektor Madya, pada Fakultas Pertanian Universitas Syiah Kuala \\ Email: keude_bing@yahoo.co.id
}

\begin{abstract}
ABSTRAK
Penelitian ini bertujuan untuk mempelajari pola migrasi masyarakat pesisir, mengidentifikasi determinan migrasi, mengkaji keterkaitan antara arus tenaga kerja, uang, barang dan jasa karena migrasi. Penelitian dilakukan pada bulan September-Oktober 2009 dengan menggunakan metode survey pada migran di daerah asal dan daerah tujuan migrasi. Responden yang dipilih adalah migran berdasarkan daerah asal dan daerah tujuan migrasi berjumlah 45 responden. Hasil penelitian ini menunjukkan bahwa migrasi dari daerah pesisir didorong oleh kelangkaan potensi ikan di perairan pesisir dan terbatasnya akses masyarakat terhadap perekonomian desa serta tersedianya pekerjaan di daerah tujuan migrasi. Keputusan bermigrasi karena jaminan pekerjaan. Pola migrasi umumnya adalah migrasi sirkulasi: mingguan dan bulanan. Migrasi itu mendorong terjadinya aliran tenaga kerja, uang dan barang antara daerah asal migrasi dan daerah tujuan migrasi. Secara ekonomi migrasi tersebut memberi dampak positif terhadap pertumbuhan perekonomian di desa asal migran dan daerah tujuan migran. Rata-rata jumlah yang bermigrasi per keluarga adalah sekitar 2 orang dan jumlah uang yang dikirim karena migrasi ke desa asal migran mencapai Rp. 500 juta per bulan. Migrasi cenderung mendorong terjadinya pengelompokan masyarakat menurut pekerjaan dan tempat tinggal di daerah tujuan migrasi, karena adanya hubungan "patron client" antara pemilik modal (patron) dan migran (client). Migrasi merupakan salah satu alternatif masyarakat pesisir untuk keluar dari masalah kemiskinan dan memenuhi kebutuhan pangan rumah tangganya. Hasil penelitian ini merekomendasikan agar program-program bantuan termasuk corporate social responsibility (CSR) yang masuk ke desa pesisir harus dikonsolidasikan dengan modal/aset yang dihimpun oleh para migran untuk menjadi pengungkit perekonomian desa pesisir.
\end{abstract}

Kata Kunci: Migrasi, Kemiskinan, Rumahtangga, Konsumsi, Pesisir

\section{Abstract: Analysis of Migration and Household Consumption Pattern in the Coastal Villages Related to Poverty and Food Resiliency. By: Armen Zulham,Subhechanis Saptanto, Retno E. Rahmawati,Lindawati, Teuku Fauzi ${ }^{2}$}

The purpose of this research was to study the migration pattern, to identify the determinant of migration, to investigate the dependency between labor movement, money, good and services. The data were collected in September 2009 and October 2009 by using survey method. Respondents were migrant based on migrant origin and migrant destination accounted for as 45 person. Results of the study showed as the following: migration from coastal villages where due to the depletion of fish in coastal water, limited access in local economic gain, and the availability of occupation in labor destination places. Weekly and monthly migration (periodic) pattern are common in both migrant destination and origin areas. Migration persuades the movement of labor, money, good and services between labor destination and origin places. From economic point of view, migration gives a positive impact to migrant destination and origin areas, respectively. In an average, 2 labors in each household in coastal villages were migrant, and Rp. 500 million were transfer to each respective village. Migration tends to push establishing society group according to type of recepation and residential place in the migration destination due to patron client relationship. Migration for the coastal community seems, to be one alternative to alleviate poverty and provide food for household. Results of the research recommend that aid's programs including the corporate social responsibility (CSR) in coastal village should be consolidated with the accumulate asset of the migrant in stimulating economic development of their respective village. 


\section{PENDAHULUAN}

Mobilitas tenaga kerja mencakup aspek yang luas, bukan hanya tentang perpindahan tenaga kerja karena keinginan sendiri (voluntary) tetapi juga terkait dengan perpindahan tenaga kerja secara paksa (involuntary) dari suatu tempat ke lokasi lain. Migrasi pada penelitian ini didefinisikan sebagai perpindahan tenaga kerja dari desadesa pesisir ke daerah tujuan migrasi (kota/desa pesisir lain/pusat pertumbuhan ekonomi) karena keinginan sendiri (voluntary) yang didesak oleh motif ekonomi.

Teori-teori tentang migrasi tenaga kerja terus berkembang mulai dari model gravitasi migrasi, push and pull theory, buffer theory (Hutoon, 1998), regulation of labor market (Bauder, 2006), dan pendekatan anthropometric (Cliggett and Crooks, 2007). Secara subtansial artikel tentang mobilitas tenaga kerja tersebut dapat dikategorikan dalam dua kelompok: pertama, melihat migrasi merupakan arus tenaga kerja sebagai akibat keterbatasan akses terhadap sumberdaya dan tidak adanya peluang ekonomi pada daerah asal migran (Ullah, 2004), migrasi demikian dikenal sebagai occupational mobility. Kedua, merupakan perpindahan penduduk dari satu negara ke negara lain untuk mendapatkan pangan dan keamanan (Clark-Kazak, 2008; Moran-Taylor, 2009) serta untuk meningkatkan pendapatan keluarga (Nielsen, 2009). Migrasi ini lebih dikenal sebagai geographical mobility.

Di Indonesia occupational mobility banyak terjadi, termasuk migrasi tenaga kerja di desa-desa pesisir. Saat ini migrasi tenaga kerja pada desa-desa pesisir tersebut dianggap sebagai hal yang wajar. Perhatian terhadap migrasi banyak dilakukan terhadap kasus migran dari sentra pertanian ke kotakota besar, dengan harapan akan dapat diformulasikan program pembangunan di daerah asal migran, seperti program Inpres Desa Tertinggal/IDT (Sumodiningrat, 2007) dan program pembangunan di daerah perkotaan seperti program Penyandang Masalah Kesejahteraan Sosial (Soegijoko, 2005).

Mobilitas migran dari desa pesisir ke daerah tujuan migrasi banyak ditentukan oleh keterikatan migran dengan struktur sosial ekonomi di daerah asal dan daerah tujuan. Pertama, jika keterikatan terhadap struktur sosial ekonomi desanya sangat kuat maka migrasi itu tidak terjadi. Kedua, jika keterikatan migran terhadap struktur sosial ekonomi desa semakin menipis dan dengan daerah tujuan migrasi sangat kuat, maka mobilitas tersebut akan terhenti dan akan timbul migran permanen. Ketiga, jika kebutuhan migran di desa pesisir kurang terpenuhi dan ikatan penduduk terhadap struktur sosial ekonomi desa pesisir sangat kuat maka akan terjadi migrasi dari desa pesisir ke daerah tujuan migrasi. Terkait dengan butir terakhir, maka terdapat dua jenis migrasi, yaitu: migrasi komuter: perpindahan penduduk harian (komutasi) dari desa-desa pesisir ke kota, dan migrasi periodik atau musiman (sirkulasi) sebagaimana yang diungkapkan oleh Colter (1984) dan Anitawati (1986).

Penelitian untuk melihat mobilitas tenaga kerja dari daerah asal migran di desa-desa pesisir ke daerah tujuan migrasi sangat penting, karena pergerakan tersebut menyebabkan alokasi sumberdaya di daerah asal migran tidak optimal. Sehingga diperlukan pendekatan program pembangunan yang tepat, agar perekonomian masyarakat pesisir dapat berkembang dan tidak merusak sumberdaya alam.

Saat ini pada desa-desa pesisir banyak terdapat program pembangunan dengan label pemberdayaan masyarakat, basis pengembangan pemberdayaan ekonominya bersifat top-down, dan cenderung mengabaikan kondisi sumberdaya alam dan karakteristik masyarakat setempat. Program demikian dianggap menjadi stimulus ekonomi desa dan diharapkan dapat menghambat migrasi dari desa pesisir ke daerah tujuan migrasi (Prabowo etal. 2004). 
Migrasi dari desa pesisir itu, mendorong terjadinya aliran produk/hasil perikanan desa pesisir ke kota, dan mengalirnya barangbarang konsumsi (hasil industri) serta peralatan rumahtangga ke desa-desa pesisir, dan diikuti dengan adanya transfer uang karena arus tenaga kerja dan arus barang antar dua wilayah itu. Di samping itu, mobilitas tenaga kerja tersebut terjadi karena di desa pesisir terjadi ketidakseimbangan pertumbuhan kesempatan kerja dan pertumbuhan angkatan kerja (Noekman dan Erwidodo, 1992) serta terbatasnya peluang ekonomi, walaupun akses terhadap sumberdaya relatif mudah. Dengan demikian migrasi komutasi atau sirkulasi antara desa pesisir dan daerah tujuan migrasi, merupakan upaya rumahtangga perikanan untuk melepaskan diri dari kemiskinan. Migrasi juga mendorong perubahan pola konsumsi rumahtangga, dan membantu menyelesaikan masalah kerentanan pangan pada rumahtangga perikanan.

Pada sisi lain migrasi tersebut dapat juga merupakan cerminan terjadinya polarisasi penguasaan aset produktif dan sumberdaya di desa pesisir, sehingga mendorong penduduk yang tidak punya akses terhadap sumberdaya, keluar dari desa. Saat ini disadari, lapangan kerja produktif di desa pesisir tidak menarik bagi masyarakat yang mempunyai pendidikan formal, mereka cenderung bekerja pada sektor lain di kota. Dengan kata lain mobilitas penduduk tersebut disebabkan juga oleh terbatasnya kesempatan kerja di desa pesisir, dan rendahnya perolehan pendapatan di desa pesisir. Dari aspek ekonomi migrasi tersebut mengandung dua harapan yaitu mendapat pekerjaan dan memperoleh pendapatan yang tinggi. Majunya pertumbuhan ekonomi di daerah tujuan migrasi yang tidak diikuti oleh pertumbuhan ekonomi di desa-desa pesisir menimbulkan berbagai dampak negatif yang saat ini seharusnya menjadi fokus perhatian pembangunan, terutama terkait dengan isu kemiskinan, pemerataan dan ketahanan pangan.
Tujuan umum penelitian ini adalah untuk memberi alternatif rekomendasi pengembangan perekonomian desa pesisir. Tujuan lain adalah (1) Mempelajari pola migrasi di desa pesisir terkait dengan kemiskinan dan kerentanan pangan, mengidentifikasi determinannya, dampak positif dan negatif dari aktifitas tersebut; (2) Mengkaji keterkaitan antara dinamika tenaga kerja desa dan kota dengan arus barang dan kapital antara dua daerah ini serta mengkaji sejauh mana migrasi tersebut berdampak positif terhadap redistribusi pendapatan serta mendorong pertumbuhan di desa pesisir sehingga dapat mengurangi kemiskinan dan menjamin perolehan pangan.

\section{METODOLOGI}

\section{Kerangka Analisis}

Berbagai studi tentang migrasi di pedesaan Jawa menunjukkan mobilitas tenaga kerja sangat tergantung pada dinamika pemanfaatan sumberdaya alam. Di daerah pertanian tanaman pangan, di Jawa mobilitas ini sangat erat kaitannya dengan masuknya traktor, serta pengunaan benih unggul yang memangkas kesempatan kerja di pedesaan (Gunawan dan Erwidodo, 1992).

Searah dengan di desa-desa pertanian, maka di desa pesisir dinamika tenaga kerja juga tergantung pada pemanfaatan sumberdaya alam (potensi ikan). Pemanfaatan potensi ikan tersebut erat kaitannya dengan masuknya teknologi penangkapan yang meliputi penggunaan motor tempel dan alat tangkap moderen.

Terkait dengan pemanfaatan potensi ikan pada perairan di daerah pesisir, maka ikan yang ada di perairan itu merupakan sumberdaya yang renewable. Artinya jika tidak ada teknologi atau alat tangkap yang digunakan untuk menangkap ikan pada perairan itu, maka dinamika potensi ikan ditentukan oleh tiga parameter: pertama, tingkat kelahiran (recruitment); kedua, pertumbuhan alami, dan ketiga kematian alami. Namun, jika teknologi atau alat tangkap 
mulai digunakan untuk menangkap ikan pada perairan pesisir tersebut, maka dinamika potensi ikan dalam perairan ditentukan oleh besarnya effort (teknologi dan alat tangkap) penangkapan ikan. Sejalan dengan pemikiran Schaefer (1957), makin besar effort akan makin cepat potensi ikan itu terkuras demikian sebaliknya.

Dengan demikian ekspansi effort dalam jangka panjang, akan menyebabkan semakin rendahnya hasil tangkapan, sehingga akan mendorong rasionalisasi teknologi dan alat tangkap. Dampaknya adalah kesempatan kerja yang tersedia tidak mampu menampung jumlah tenaga kerja yang ada. Akibatnya terjadi migrasi dari desa pesisir ke pusat-pusat pertumbuhan ekonomi. Migrasi tersebut semakin nyata karena didukung oleh semakin sempurnanya teknologi komunikasi dan baiknya sarana serta prasarana transportasi.

\section{Dasar Pemilihan Lokasi}

Perilaku migrasi difokuskan pada mobilitas tenaga kerja pesisir (terutama rumahtangga perikanan). Lokasi sumber informasi tersebut dikelompokkan menjadi dua, yaitu: pertama, daerah asal migrasi dan kedua, daerah tujuan migrasi. Daerah tersebut merupakan daerah yang perekonomiannya dominan tergantung pada aktivitas perikanan.

\section{Daerah Asal Migrasi}

Migrasi merupakan fenomena aktual yang tidak dapat dipisahkan dari kondisi sosial ekonomi masyarakat, dan akses rumahtangga terhadap sumber-sumber ekonomi setempat (sumberdaya alam, lahan, akses pasar dan lainnya). Teori menyatakan pergerakan penduduk dengan motif ekonomi akan terjadi, jika akses rumahtangga terhadap sumber ekonomi tersebut semakin sulit, hal ini disebabkan oleh:

1. Sumberdaya alam (seperti potensi ikan dan lainnya) yang menjadi mata pencaharian rumahtangga semakin menipis.
2. Kepemilikan aset-aset produktif dikuasai oleh sekelompok masyarakat dan tidak didistribusikan ke kelompok masyarakat yang lain.

3. Terhambatnya akses rumahtangga terhadap sumber-sumber ekonomi setempat, karena berbagai kendala seperti: modal, tingkat pendidikan. Akibatnya sebagian keluarga mendorong anggota keluarganya bekerja di luar desa.

4. Akses dan pangsa masyarakat terhadap konsumsi pangan dan non pangan.

Empat hal yang disebut di atas merupakan kunci penting untuk melihat tingkat kemiskinan dan kerentanan pangan pada desa pesisir di daerah asal migran. Masyarakat di Desa Dadap, Desa Eretan Wetan, Desa Eretan Kulon, dan Desa llir dapat merepresentasikan fenomena tersebut. Di daerah pesisir Kabupaten Indramayu terdapat 38.000 orang nelayan, kondisi ini menyebabkan daya dukung potensi perikanan tidak dapat mendukung kehidupan masyarakat. Implikasinya sangat luas, terutama terkait dengan tingkat pendapatan, ketersediaan lapangan kerja dan perkembangan ekonomi lokal.

\section{Daerah Tujuan Migrasi}

Daerah tujuan migrasi merupakan daerah yang mempunyai daya tarik ekonomi yang kuat. Daerah ini biasanya memiliki karakteristik sebagai berikut:

1. Kawasan tersebut memiliki aktifitas ekonomi yang berkembang, dan memerlukan tenaga kerja terutama buruh kasar untuk kegiatan produksi produk primer dan pengolahan produk primer menjadi produk setengah jadi.

2. Memberi akses kepada pendatang yang didukung oleh infrastruktur yang relatif baik, sehingga daerah tujuan ini mempunyai keterkaitan ke depan yang kuat dengan pusat kota dan keterkaitan ke belakang dengan daerah asal migran. 
Tabel 1. Jumlah Responden di Daerah Asal dan Daerah Tujuan Migrasi.

Table 1. Number of Respondent in Migrant Origin and Destination.

\begin{tabular}{llc}
\hline \multicolumn{1}{c}{ Tipe Daerah / } & Desa/Villages & \multicolumn{1}{c}{$\begin{array}{c}\text { Jumlah Responden (Orang)/ } \\
\text { Number of Respondent (Persons) }\end{array}$} \\
\hline Daerah asal migran (Kab. Indramayu)/ & Dadap & 9 \\
Migrant origin (Indramayu District) & Eretan Wetan & 3 \\
& Eretan Kulon & 8 \\
& llir & 10 \\
Daerah tujuan migran (Jakarta Utara)/ & Kalibaru & 10 \\
Migrant Destination (North Jakarta) & Cilincing & 5 \\
& & \\
\hline
\end{tabular}

3. Ekonomi daerah tujuan migran terkonsentarsi pada kegiatan tertentu dan dikelola oleh beberapa pemilik modal, sehingga pemilik modal menjadi kunci penting sebagai penarik migran ke daerah tujuan migrasi.

Kelurahan Cilincing dan Kelurahan Kalibaru merupakan contoh daerah pesisir di Jakarta yang menjadi tujuan migrasi dari berbagai daerah pesisir Pantura dan Sulawesi. Daerah ini terdapat komunitas migran yang berasal dari desa Ilir di Indramayu, Brebes, Tegal serta Sulawesi.

\section{Jenis dan Sumber Data}

Data yang dikumpulkan terdiri dari data primer dan data sekunder. Data primer merupakan data utama dari penelitian ini, yang dikumpulkan melalui wawancara dengan responden yang melakukan kegiatan migrasi, di lokasi tujuan migrasi dan dilokasi asal migrasi. Data sekunder merupakan data tentang karakteristik daerah migran. Jumlah responden yang diwawancara dapat diperhatikan pada Tabel 1.

\section{Waktu Pelaksanaan Penelitian}

Pengambilan data untuk penelitian ini dilakukan pada bulan September 2009 pada lokasi daerah tujuan migrasi sedangkan pada daerah asal migrasi dilakukan pada bulan Oktober 2009.

\section{Metoda Analisis Data}

Tulisan ini menggunakan pendekatan deskriptif analisis dengan bantuan statistik sederhana. Data yang dianalisis adalah hasil wawancara dengan responden di daerah asal migrasi dan daerah tujuan migrasi. Atas dasar data tersebut dicoba mengidentifikasi determinan migrasi masyarakat pesisir secara luas, serta melihat bagaimana migrasi tersebut dapat meredistribusi aset produktif untuk mengatasi kemiskinan dan kerentanan pangan.

\section{HASIL DAN PEMBAHASAN}

\section{Karakteristik Responden}

Tabel 2 menunjukkan gambaran mengenai umur migran pada daerah tujuan migrasi dan daerah asal migrasi. Umur migran yang paling dominan melakukan kegiatan migrasi berkisar antara $31-50$ tahun $(62,2 \%$ dari total responden).

Usia 31 tahun sampai 50 tahun merupakan usia produktif yang potensial melakukan kegiatan migrasi sirkulasi. Dari kelompok umur tersebut $14,3 \%$ dan $25 \%$ terdapat di Cilincing dan Kalibaru. Sementara $21,4 \%$ terdapat di Dadap, 14,3\% terdapat di eretan Kulon dan 25\% ada di Desa Ilir. Di Eretan Wetan jarang ditemui migran sirkulasi. Di Kalibaru, desa Ilir, dan Eretan Kulon yang bermigrasi umumnya dari kelompok umur ? 30 tahun. Secara umum, migran tersebut banyak 
Tabel 2. Usia Migran Pada Daerah Tujuan dan Asal Migrasi.

Table 2. Ages of Migrant in Destination and Origin Areas.

\begin{tabular}{|c|c|c|c|c|c|c|c|c|c|}
\hline \multirow{3}{*}{$\begin{array}{l}\text { Lokasi/ } \\
\text { Locations }\end{array}$} & \multirow{3}{*}{$\begin{array}{c}\text { Kelurahan/ } \\
\text { Kecamatan/ Village/ } \\
\text { Sub-Districts }\end{array}$} & \multicolumn{6}{|c|}{ Usia Migran/ Ages } & \multirow{2}{*}{\multicolumn{2}{|c|}{$\begin{array}{c}\text { TOTAL/ } \\
\text { Total }\end{array}$}} \\
\hline & & \multicolumn{2}{|c|}{$\begin{array}{c}? 30 \\
\text { Tahun/ Year }\end{array}$} & \multicolumn{2}{|c|}{$\begin{array}{c}31-50 \\
\text { Tahun/ Year }\end{array}$} & \multicolumn{2}{|c|}{$\begin{array}{c}\text { ऽ50 } \\
\text { Tahun/Year }\end{array}$} & & \\
\hline & & $f$ & $\%$ & $f$ & $\%$ & $\mathrm{f}$ & $\%$ & $f$ & $\%$ \\
\hline \multirow{2}{*}{$\begin{array}{l}\text { Daerah tujuan } \\
\text { migrasi/Migrant } \\
\text { destinations }\end{array}$} & \multirow{2}{*}{$\begin{array}{l}\text { Cilincing } \\
\text { Kalibaru }\end{array}$} & 1 & 9,1 & 4 & 14,3 & 0 & 0,0 & 5 & 11,1 \\
\hline & & 3 & 27,3 & 7 & 25,0 & 0 & 0,0 & 10 & 22,2 \\
\hline \multirow{4}{*}{$\begin{array}{l}\text { Daerah asal } \\
\text { migrasi/Migrant } \\
\text { origin }\end{array}$} & Dadap & 0 & 0,0 & 6 & 21,4 & 3 & 50,0 & 9 & 20,0 \\
\hline & Eretan Kulon & 3 & 27,3 & 4 & 14,3 & 1 & 16,7 & 8 & 17,8 \\
\hline & Eretan Wetan & 1 & 9,1 & 0 & 0,0 & 2 & 33,3 & 3 & 6,7 \\
\hline & Ilir & 3 & 27,3 & 7 & 25,0 & 0 & 0,0 & 10 & 22,2 \\
\hline \multicolumn{2}{|c|}{ Total/Total } & 11 & 100,0 & 28,0 & 100,0 & 6,0 & 100,0 & 45,0 & 100,0 \\
\hline \multicolumn{2}{|c|}{ Persentase/Percentage } & 24,5 & $\mathbf{x}$ & 62,2 & $\mathbf{x}$ & 13,3 & $\mathbf{x}$ & 100 & $x$ \\
\hline
\end{tabular}

Sumber: Diolah dari Data Primer (2009)/ Source: Processed from Primary Data (2009)

terdapat di Kalibaru (22\%), Dadap (20\%), Eretan Kulon (17,8\%), dan Ilir (22\%).

Dari total responden tersebut $75,6 \%$ migran yang melakukan migrasi adalah lakilaki, dan sisanya 24,4 persen adalah perempuan. Dari 11 orang responden perempuan yang melakukan migrasi tersebut $27,3 \%$ terdapat di Kalibaru adalah sebagai buruh pengolah dan $72,7 \%$ terdapat di Desa Ilir, pekerjaan mereka adalah sebagai buruh pengolah di desa lain di pesisir Kabupaten Indramayu (Tabel 3).

Tabel 3. Jenis Kelamin Migran di Daerah Asal dan Tujuan Migrasi

Table 3. Sex of Migrant in Origin and Destination Areas

\begin{tabular}{|c|c|c|c|c|c|c|c|}
\hline \multirow{3}{*}{$\begin{array}{l}\text { Lokasi / } \\
\text { Locations }\end{array}$} & \multirow{3}{*}{$\begin{array}{c}\text { Kelurahan/ } \\
\text { Kecamatan / } \\
\text { Villages/Subdistricts }\end{array}$} & \multicolumn{4}{|c|}{ Jenis Kelamin /Sex } & \multirow{2}{*}{\multicolumn{2}{|c|}{$\begin{array}{l}\text { Total / } \\
\text { Total }\end{array}$}} \\
\hline & & \multicolumn{2}{|c|}{$\begin{array}{c}\text { Laki-Laki/ } \\
\text { Male }\end{array}$} & \multicolumn{2}{|c|}{$\begin{array}{c}\text { Perempuan / } \\
\text { Female }\end{array}$} & & \\
\hline & & $f$ & $\%$ & $f$ & $\%$ & $f$ & $\%$ \\
\hline \multirow{2}{*}{$\begin{array}{l}\text { Daerah tujuan } \\
\text { migrasi/Migrant } \\
\text { destination }\end{array}$} & Cilincing & 5 & 14,7 & 0 & 0,0 & 5 & 11,1 \\
\hline & Kalibaru & 7 & 20,6 & 3 & 27,3 & 10 & 22,2 \\
\hline \multirow{3}{*}{$\begin{array}{l}\text { Daerah asal } \\
\text { migrasi /Migrant } \\
\text { origin }\end{array}$} & $\begin{array}{l}\text { Dadap } \\
\text { Eretan Kulon }\end{array}$ & $\begin{array}{l}9 \\
8\end{array}$ & $\begin{array}{l}26,5 \\
23,5\end{array}$ & $\begin{array}{l}0 \\
0\end{array}$ & $\begin{array}{l}0,0 \\
0,0\end{array}$ & $\begin{array}{l}9 \\
8\end{array}$ & $\begin{array}{l}20,0 \\
17,8\end{array}$ \\
\hline & Eretan Wetan & 3 & 8,8 & 0 & 0,0 & 3 & 6,7 \\
\hline & Ilir & 2 & 5,9 & 8 & 72,7 & 10 & 22,2 \\
\hline \multicolumn{2}{|c|}{ Total/Total } & 34 & 75,0 & 11 & 25,0 & 45 & 100,0 \\
\hline
\end{tabular}


Tabel 4. Tingkat Pendidikan Responden di Daerah Asal dan Tujuan Migrasi.

Table 4. Respondent Education Level in Migrant Origin and Destination.

\begin{tabular}{|c|c|c|c|c|c|c|c|c|c|c|c|}
\hline \multirow{3}{*}{$\begin{array}{l}\text { Lokasi/ } \\
\text { Location }\end{array}$} & \multirow{3}{*}{$\begin{array}{l}\text { Kelurahan/ } \\
\text { Kecamatan/ } \\
\text { Villages / } \\
\text { Sub } \\
\text { Districts }\end{array}$} & \multicolumn{4}{|c|}{ Pendidikan Migran/ } & \multicolumn{4}{|c|}{ Migrant Education Level } & & \\
\hline & & \multicolumn{2}{|c|}{$\begin{array}{c}\text { Tidak } \\
\text { Sekolah/Informal } \\
\text { School }\end{array}$} & \multicolumn{2}{|c|}{$\begin{array}{c}\text { SD/ } \\
\text { Elementary } \\
\text { School }\end{array}$} & \multicolumn{2}{|c|}{$\begin{array}{c}\text { SMP/Junior } \\
\text { High } \\
\text { School }\end{array}$} & \multicolumn{2}{|c|}{$\begin{array}{l}\text { SMA/ } \\
\text { Senior } \\
\text { High } \\
\text { School }\end{array}$} & \multicolumn{2}{|c|}{ Total/ Total } \\
\hline & & $f$ & $\%$ & $f$ & $\%$ & $\mathrm{f}$ & $\%$ & $f$ & $\%$ & $f$ & $\%$ \\
\hline \multirow{2}{*}{$\begin{array}{l}\text { Daerah tujuan } \\
\text { migrasi/Migrant } \\
\text { destination }\end{array}$} & Cilincing & 1 & 2,2 & 3 & 6,7 & 1 & 2,2 & 0 & 0,0 & 5 & 11,1 \\
\hline & Kalibaru & 1 & 2,2 & 5 & 11,1 & 4 & 8,9 & 0 & 0,0 & 10 & 22,2 \\
\hline \multirow{4}{*}{$\begin{array}{l}\text { Daerah asal } \\
\text { migrasi/Origin } \\
\text { migrant }\end{array}$} & Dadap & 4 & 8,9 & 4 & 8,9 & 0 & 0,0 & 1 & 2,2 & 9 & 20,0 \\
\hline & Eretan Kulon & 3 & 6,7 & 5 & 11,1 & 0 & 0,0 & 0 & 0,0 & 8 & 17,8 \\
\hline & Eretan Wetan & 1 & 2,2 & 2 & 4,4 & 0 & 0,0 & 0 & 0,0 & 3 & 6,7 \\
\hline & Ilir & 3 & 6,7 & 2 & 4,4 & 0 & 0,0 & 0 & 0,0 & 10 & 22,2 \\
\hline \multicolumn{2}{|c|}{$\begin{array}{l}\text { Jumlah/Persentase/ } \\
\text { Total/Percentage }\end{array}$} & 13 & 28,9 & 21 & 46,7 & 5 & 11,1 & 1 & 2,2 & 45 & 100,0 \\
\hline
\end{tabular}

Sumber: Diolah dari Data Primer (2009)/ Source: Processed from Primary Data (2009)

Di daerah tujuan migrasi responden yang mempunyai anggota keluarga 4 orang dan lebih dari 5 orang masing-masing adalah 18\% dan $16 \%$. Data ini menunjukkan tingginya pertumbuhan penduduk di daerah tujuan migrasi. Artinya di Kalibaru dan Cilincing tingkat kepadatan penduduk sangat tinggi. Kepadatan penduduk yang demikian membuat daerah Kalibaru dan Cilincing menjadi kawasan yang kumuh karena banyak migran yang keterampilannya terbatas.

Migran dari daerah pesisir yang masuk ke Cilincing dan Kalibaru hanya akan bekerja di daerah tersebut, mereka sulit mencari kerja di luar daerah itu, karena tingkat pendikan mereka rata-rata adalah sekolah dasar (Tabel 4). Kehadiran mereka di daerah tujuan migrasi umumnya diperlukan oleh pengusaha pengolahan ikan dan perikanan yang ada di Kalibaru dan Cilincing.

Secara keseluruhan baik di daerah tujuan migrasi dan daerah asal migrasi terdapat $46,7 \%$ migran pernah mengenyam pendidikan sekolah dasar, $28,9 \%$ tidak sekolah, $11,1 \%$ SMP dan hanya $2 \%$ mengenyam pendidikan SMA. Kualitas migran di pesisir ini sangat jauh tertinggal dibandingkan dengan kualitas migran dari sektor pertanian tanaman pangan (Gunawan dan Erwidodo, 1992). Dengan demikian dapat dipahami bahwa migran dari desa pesisir ini sangat sulit memperoleh pekerjaan di luar kegiatan perikanan, di luar kegiatan perikanan pada umumnya mereka hanya menjadi buruh kasar.

Sementara kondisi lingkungan, di daerah tujuan migrasi yang meliputi status rumah, kondisi rumah, jenis lantai rumah, jenis dinding terbanyak, jenis atap, sumber penerangan, bahan bakar untuk memasak, sumber air untuk konsumsi rumahtangga, fasilitas MCK (mandi, cuci, kakus), sistem saluran air limbah dan pemeliharaan unggas, menunjukkan: sebagian besar migran di daerah tujuan umumnya menyewa rumah pada daerah tujuan migrasi. Biaya sewa rumah berkisar antara Rp. 200 ribu sampai Rp. 300 ribu per bulan. Bangunan rumah pada umumnya adalah semi permanen dengan dinding dari kayu dan atap menggunakan seng.

Di Cilincing sebagian migran ditemui masih tinggal dalam perahu. Sumber energi untuk penerangan yang digunakan migran 
adalah lampu minyak tanah dan PLN, sedangkan bahan bakar untuk memasak menggunakan kompor minyak tanah. Perlu dicatat baik di Cilincing maupun di Kalibaru para migran umumnya membeli makanan jadi. Sumber air untuk konsumsi rumahtangga sangat tergantung dari pasokan pengecer. Bisnis air bersih untuk konsumsi cukup berkembang di daerah ini.

Fasilitas MCK di daerah Kalibaru pada umumnya berada dalam rumah masingmasing, sedangkan di daerah Cilincing fasilitas ini sifatnya milik umum. Adapun sistem saluran air limbah rumahtangga merupakan saluran air terbuka, dimana air limbah tersebut mengeluarkan bau busuk.

Berdasarkan uraian di atas dapat diperoleh informasi bahwa infrastruktur yang mendukung migran pada daerah tujuan migrasi sangat jauh dari kondisi lingkungan yang sehat. Bagi migran yang penting dapat memperoleh makanan, ada tempat istirahat dan mendapatkan pekerjaan untuk dapat memperbaiki kondisi hidup mereka di kampung.

Sedangkan pada daerah asal migran, menunjukkan kepemilikan rumah tempat tingga responden umumnya milik sendiri. Kondisi rumahnya pada umumnya permanen, dengan lantai berkeramik, berdinding tembok dan beratap genteng beton.

Di daerah asal migrasi, sumber air untuk konsumsi harus membeli dari pengecer dengan harga Rp. 5 ribu per galon. Sementara bahan bakar untuk memasak adalah gas. Pengetahuan tentang penggunaan gas untuk memasak masih awam, karena itu sosialisasi tentang keamanan, kepraktisan penggunaan gas menjadi sangat penting. Pada sisi lain pada daerah asal migran ini sistem saluran air untuk pembuangan limbah rumahtangga cenderung menggunakan sistem saluran yang ter tutup.

Penggunaan kompor gas oleh masyarakat migran terkait dengan pengurangan subsidi bahan bakar minyak. Tabung gas dan asesoris perangkatnya diperoleh dari program pemerintah tentang konversi minyak tanah.

\section{Faktor Pendorong dan Penarik Migrasi}

Tabel 5, memberi gambaran tentang faktor-faktor yang menyebabkan responden terdorong melakukan migrasi. $60 \%$ responden melakukan migrasi karena di desa tidak ada pekerjaan. Selanjutnya sekitar $31,1 \%$ responden mengatakan tidak memiliki akses terhadap sumberdaya dan potensi ekonomi desa. Di samping itu hanya sekitar $8,9 \%$ responden sulit menjual hasil tangkapannya.

Dorongan melakukan migrasi dari desa asal migran tersebut, semakin diperkuat dengan adanya faktor penarik dari dari daerah tujuan migrasi. Faktor penarik migrasi yang paling berperan adalah tersedianya lapangan kerja di daerah tujuan migrasi. Pada kelompok nelayan ini upah yang diterima belum menjadi acuan penting untuk bermigrasi. Di Kalibaru 10 responden mengatakan mereka ke Kalibaru karena mereka akan bekerja sebagai buruh industri pengolahan. Di Cilincing seluruh nelayan yang berasal dari Indramayu bermigrasi ke daerah tersebut karena untuk menangkap ikan dan menjual hasil tangkapan ikan harganya lebih baik dan pembayarannya langsung dibayar tunai.

Daerah asal migran yang lapangan kerjanya sangat terbatas adalah di desa Eretan Kulon dan Desa llir. Hal ini mendorong migran tersebut mencari kerja di luar desa. Nelayan dari dua desa ini umumnya menangkap ikan ke berbagai lokasi di perairan Kepulauan Seribu, Pantura Jawa Barat, perairan Banten, Laut Cina Selatan dan Selat Karimata. Lokasi menangkap ikan dan migrasi nelayan Indramayu dapat diperhatikan pada Tabel 6. Informasi dari Tabel 6 tersebut menunjukkan sekitar $70 \%$ nelayan Indramayu tersebut bermigrasi selama sebulan. Artinya nelayan tersebut pulang ke Indramayu setelah sebulan di daerah tujuan. Sementara itu sekitar $26,7 \%$ nelayan Indramayu pulang ke desanya di Indramayu setelah seminggu di daerah tujuan (Tabel6). 
Tabel 5. Alasan Responden Bermigrasi.

Table 5. Respondent Responsibility of Migration.

\begin{tabular}{|c|c|c|c|c|c|c|c|c|c|}
\hline \multirow{3}{*}{$\begin{array}{l}\text { Lokasi / } \\
\text { Location }\end{array}$} & \multirow{3}{*}{$\begin{array}{l}\text { Kelurahan/ } \\
\text { Kecamatan / } \\
\text { Villages/ } \\
\text { Sub } \\
\text { Districts }\end{array}$} & \multicolumn{6}{|c|}{ Alasan Migrasi/Reason of Migration } & \multirow{2}{*}{\multicolumn{2}{|c|}{ Total / Total }} \\
\hline & & \multicolumn{2}{|c|}{$\begin{array}{c}\text { Sulit } \\
\text { Menjual } \\
\text { Hasil/ } \\
\text { Difficult to } \\
\text { Sold } \\
\text { Product }\end{array}$} & \multicolumn{2}{|c|}{$\begin{array}{c}\text { Tidak ada } \\
\text { Pekerjaan } \\
\text { di Desa/No } \\
\text { Job in } \\
\text { Village }\end{array}$} & \multicolumn{2}{|c|}{$\begin{array}{c}\text { Tidak ada } \\
\text { Akses } \\
\text { Terhadap } \\
\text { Sumberdaya } \\
\text { di Desa/Have } \\
\text { no Accsess } \\
\text { to Village } \\
\text { Resources } \\
\end{array}$} & & \\
\hline & & $f$ & $\%$ & $f$ & $\%$ & $f$ & $\%$ & $f$ & $\%$ \\
\hline \multirow{2}{*}{$\begin{array}{l}\text { Daerah tujuan } \\
\text { migrasi/Migrant } \\
\text { destination }\end{array}$} & Cilincing & 0 & 0,0 & 4 & 8,9 & 1 & 2,2 & 5 & 11,11 \\
\hline & Kalibaru & 0 & 0,0 & 10 & 22,2 & 0 & 0,0 & 10 & 22,22 \\
\hline \multirow{3}{*}{$\begin{array}{l}\text { Daerah a sal } \\
\text { migrasi/ } \\
\text { Migrant origin }\end{array}$} & $\begin{array}{l}\text { Dadap } \\
\text { Eretan Kulon }\end{array}$ & $\begin{array}{l}2 \\
2\end{array}$ & $\begin{array}{l}4,4 \\
4,4\end{array}$ & $\begin{array}{l}1 \\
6\end{array}$ & $\begin{array}{c}2,2 \\
13,3\end{array}$ & $\begin{array}{l}6 \\
0\end{array}$ & $\begin{array}{c}13,3 \\
0,0\end{array}$ & $\begin{array}{l}9 \\
8\end{array}$ & $\begin{array}{l}20,00 \\
17,78\end{array}$ \\
\hline & Eretan Wetan & 0 & 0,0 & 1 & 2,2 & 2 & 4,4 & 3 & 6,67 \\
\hline & Ilir & 0 & 0,0 & 5 & 11,1 & 5 & 11,1 & 10 & 22,22 \\
\hline \multicolumn{2}{|c|}{$\begin{array}{l}\text { Jumlah/Persentase/ } \\
\text { Total/Percentage }\end{array}$} & 4 & 8,9 & 27 & 60,0 & 14 & 31,1 & 45 & 100,00 \\
\hline
\end{tabular}

Sumber: Diolah dari Data Primer (2009)/ Source: Processed from Primary Data (2009)

Tabel 6. Daerah Tujuan Migrasi Nelayan Kabupaten Indramayu.

Table 6. Migrant Destination of Indramayu's Fisherman.

\begin{tabular}{|c|c|c|c|c|c|c|c|}
\hline \multirow{2}{*}{\multicolumn{2}{|c|}{$\begin{array}{l}\text { Lokasi Migrasi / } \\
\text { Migrant Location }\end{array}$}} & \multicolumn{6}{|c|}{ Lama Migrasi /Duration of Migration } \\
\hline & & \multicolumn{2}{|c|}{$\begin{array}{l}\text { Mingguan / } \\
\text { Weekly }\end{array}$} & \multicolumn{2}{|c|}{$\begin{array}{l}\text { Bulanan/ } \\
\text { Monthly }\end{array}$} & \multicolumn{2}{|c|}{$\begin{array}{l}\text { Tahunan / } \\
\text { Yearly }\end{array}$} \\
\hline & & $\mathrm{f}$ & $\%$ & $\mathrm{f}$ & $\%$ & $f$ & $\%$ \\
\hline Jakarta & $\begin{array}{l}\text { Jakarta } \\
\text { Kamal Muara } \\
\text { Muara Angke } \\
\text { Cilincing } \\
\text { Kalibaru }\end{array}$ & $\begin{array}{l}1 \\
1 \\
2 \\
0 \\
0\end{array}$ & $\begin{array}{l}2,2 \\
2,2 \\
4,4 \\
0,0 \\
0,0\end{array}$ & $\begin{array}{l}0 \\
0 \\
5 \\
7 \\
8\end{array}$ & $\begin{array}{r}0,0 \\
0,0 \\
11,1 \\
15,6 \\
17,8\end{array}$ & $\begin{array}{l}0 \\
0 \\
0 \\
0 \\
2\end{array}$ & $\begin{array}{l}0,0 \\
0,0 \\
0,0 \\
0,0 \\
4,4\end{array}$ \\
\hline Jawa Barat & $\begin{array}{l}\text { Blanakan } \\
\text { Dadap }\end{array}$ & $\begin{array}{l}2 \\
0\end{array}$ & $\begin{array}{l}4,4 \\
0,0\end{array}$ & $\begin{array}{l}1 \\
2\end{array}$ & $\begin{array}{l}2,2 \\
4,4\end{array}$ & $\begin{array}{l}0 \\
0\end{array}$ & $\begin{array}{l}0,0 \\
0,0\end{array}$ \\
\hline Banten & $\begin{array}{l}\text { Labuan } \\
\text { Panimbang }\end{array}$ & $\begin{array}{l}0 \\
2\end{array}$ & $\begin{array}{l}0,0 \\
4,4\end{array}$ & $\begin{array}{l}1 \\
5\end{array}$ & $\begin{array}{r}2,2 \\
11,1\end{array}$ & $\begin{array}{l}0 \\
0\end{array}$ & $\begin{array}{l}0,0 \\
0,0\end{array}$ \\
\hline Kalimantan & Selat Karimata & 3 & 6,7 & 2 & 4,4 & 0 & 0,0 \\
\hline Sumatera & Laut Cina Selatan & 1 & 2,2 & 0 & 0,0 & 0 & 0,0 \\
\hline Total/Total & & 12 & 26,7 & 31 & 68,9 & 2 & 4,4 \\
\hline
\end{tabular}




\section{Determinan, Dampak Positif dan Negatif Migrasi}

Migrasi dari desa pesisir (Indramayu: Desa Dadap, Desa Eretan Kulon, Desa Eretan Wetan, dan Desa llir) ke daerah Tujuan migrasi (Jakarta Utara: Kelurahan Cilincing dan Kelurahan Kalibaru) merupakan fenomena yang telah lama terjadi namun luput dari perhatian. Fenomena ini penting dipahami karena terkait dengan akses masyarakat terhadap sumberdaya alam, penguasaan aset produktif dan perkembangan ekonomi desa.

Berbagai informasi menunjukkan migrasi pada masyarakat pantai utara Jawa Barat (seperti di wilayah Perairan Indramayu) dipicu oleh gejala overfishing pada perairan pantura. Menurut Dinas Perikanan dan Kelautan Kabupaten Indramayu (2009), di Kabupaten Indramayu terdapat terdapat 38.000 orang nelayan yang sebagian besar mengandalkan usahanya pada perairan pantai di sekitar wilayah perairan Indramayu dengan menggunakan kapal penangkap ikan ukuran 10 GT sampai 30 GT serta Perahu Motor Tempel (PMT) ukuran < $10 \mathrm{GT}$. Jumlah armada penangkapan itu bervariasi menurut desa yang ada di pesisir Indramayu. Di Desa Eretan Wetan misalnya terdapat 400 PMT ukuran < 10 GT, serta sekitar 27 kapal penangkap ikan ukuran 10 GT hingga 30 GT. Overfishing di perairan pesisir Indramayu disebabkan oleh berkembangnya PMT dalam jumlah melebihi carrying capacity potensi ikan, karena program motorisasi perikanan merupakan bagian dari program peningkatan produksi dan pengentasan kemiskinan.

Tingginya tekanan pada perairan Indramayu mendorong sebagian nelayan Indramayu menangkap ikan ke berbagai fishing ground dalam wilayah Indonesia (terutama, di perairan Kepulauan Seribu, Laut Cina Selatan, serta pada perairan Selat Sunda). Perlu dicatat hasil tangkapan ikan di sekitar perairan Indramayu terus berkurang. Informasi lapangan menunjukkan pada tahun 1980-an PTM mampu menangkap ikan sebanyak 5-7 kuintal per trip, dan saat ini hanya berkisar antara 1-2 kuintal per trip. Penangkapan ikan ke fishing ground yang semakin jauh memerlukan modal yang besar, modal tersebut biasanya disediakan oleh pemilik modal (toke) yang umumnya berada di Jakarta, Panimbang - Banten, dan daerah lain di sekitar Jakarta.

Dukungan modal dari toke yang berada dari luar Indramayu merupakan faktor penarik yang mendorong mobilitas nelayan Indramayu ke luar daerah, yang dikenal sebagai migrasi periodik atau musiman (sirkulasi) atau disebut juga sebagai migran sirkuler. Sebagian nelayan Indramayu lainnya menangkapan ikan dan menjualnya di tempat yang berbeda dan pada hari yang sama mereka kembali lagi ke desanya, mobilitas ini dikenal sebagai migrasi harian - yang dikenal sebagai migran komuter.

Tabel 7, menggambarkan pola migrasi dari responden di daerah asal migran dan di daerah tujuan migrasi. Informasi pada Tabel 7 menunjukkan bahwa migrasi tersebut terjadi pada semua desa contoh. Di daerah asal migran, migrasi komuter umumnya dilakukan oleh nelayan dengan ciri-ciri:

1. Menangkap ikan di perairan pantai seputar desa dan menjual hasil tangkapannya di desa lain.

2. Modal untuk menangkap ikan dibiayai oleh pedagang di sekitar desa tempat tinggal migran.

3. Ikatan migran dengan pedagang di sekitar desa asal dan dalam struktur ekonomi desa sangat tinggi.

Di daerah tujuan migrasi, migrasi komutasi bukan hanya dilakukan oleh nelayan, tetapi dilakukan juga oleh kelompok masyarakat lain (seperti pedagang) untuk distribusi barang dan jasa. Migrasi komutasi ini dilakukan oleh pedagang hasil perikanan (kerang hijau, ikan segar dan produk olahan) dari Kalibaru dan Cilincing ke berbagai pasar tradisional di Jakarta termasuk ke Pasar Kramatjati di Jakarta Timur.

Terdapat cukup banyak migran permanen di Kalibaru dan Cilincing, sebagian 
Tabel 7. Pola Migrasi di Daerah Asal dan Tujuan Migrasi.

Table 7. Migration Pattern in Migrant Origin and Migrant Destination.

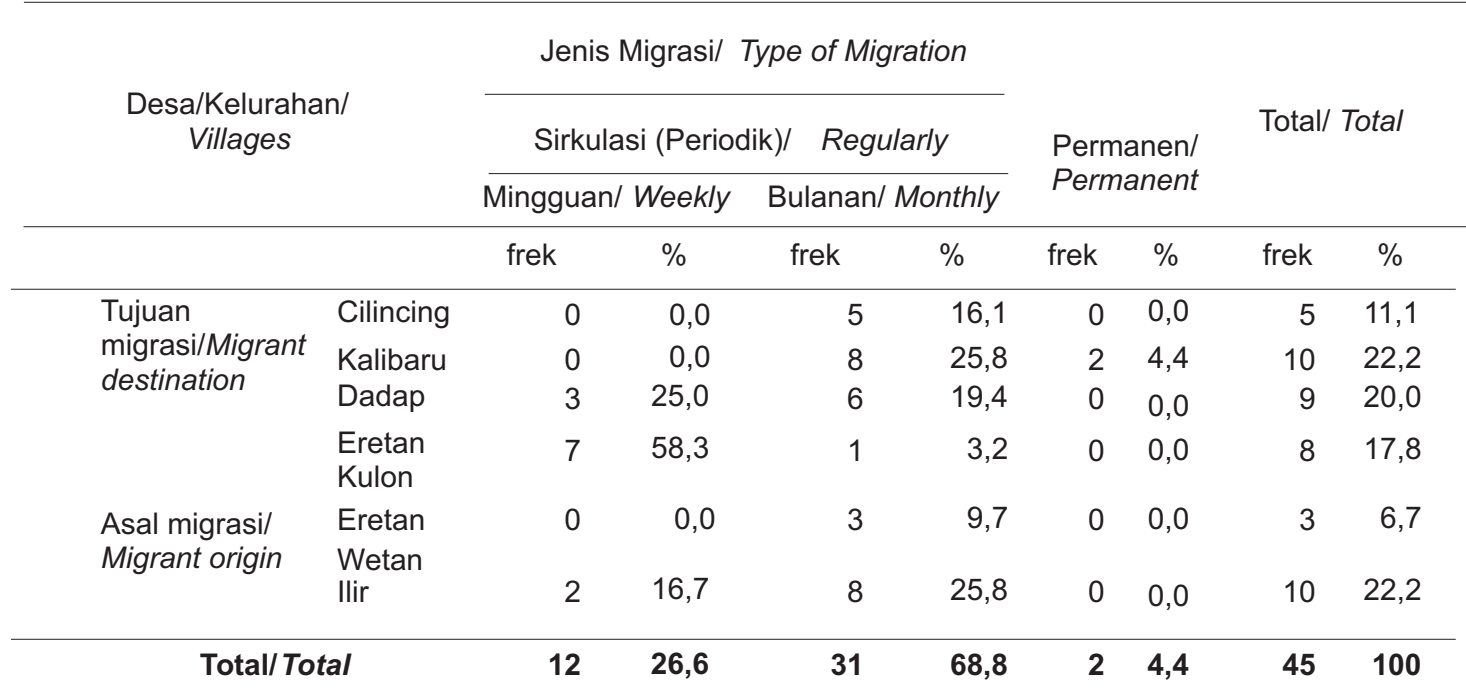

Sumber: Diolah dari Data Primer (2009)/ Source: Processed from Primary Data (2009)

mereka bekerja sebagai buruh berbagai industri. Sementara itu migran permanen yang bergerak pada aktifitas perikanan memainkan peranan yang sangat penting dalam mengerakkan ekonomi di daerah Kalibaru dan Cilincing. Nelayan-nelayan Indramayu yang pada awalnya merupakan migran sirkulasi dan berhasil di perantauan, yang kemudian mempunyai jaringan usaha yang luas selanjutnya menjadi pemodal dan menjadi "patron" masyarakat Indramayu daerah tujuan migrasi. Pemodal tersebut dalam mengembangkan usahanya memerlukan tenaga kerja dari Indramayu. Tenaga kerja ini cenderung menetap dalam waktu yang lama, bahkan mereka ada yang membawa keluarganya ke daerah tujuan migrasi. Kelompok ini dapat dikategorikan sebagai migran permanen. Kelompok migran permanen ini pulang ke kampung halamannya umumnya saat menjelang hari raya Idul Fitri dan kembali lagi ke daerah tujuan migrasi (Kalibaru atau Cilincing) beberapa minggu kemudian.

Para migran permanen tersebut mempunyai berbagai usaha seperti pengolahan kerang hijau dan produk perikanan (kerupuk kulit ikan) menjadi produk konsumsi, penyalur produk perikanan ke pedagang lain di berbagai lokasi dan restoran di Jakarta. Pengamatan lapangan menunjukkan terdapat usaha migran permanen (seperti kerupuk kulit ikan) yang harus diolah lebih lanjut di daerah asal migran (Indramayu). Setelah itu produk kulit ikan yang siap konsumsi itu dikirim kembali ke Kalibaru untuk dipasarkan pada berbagai tempat (terutama tempat hiburan malam).

$\mathrm{Di}$ daerah Kalibaru dan Cilincing ini terdapat berbagai kelompok etnis migran permanen, seperti kelompok Indramayu, kelompok Tegal, kelompok Cirebon, Kelompok Bugis, dan Kelompok Banten. Untuk mengembangkan usahanya migran permanen tersebut mencari tenaga kerja dari daerah asalnya. Perlu dicatat migran permanen tersebut sangat jarang pulang ke daerah asalnya karena untuk menjaga kelangsungan usahanya di daerah tujuan migrasi. Di daerah Indramayu setiap 2 tahun diadakan acara "ngadrang", acara ini selain bertujuan untuk mensyukuri nikmat Tuhan, dimaksudkan juga 
sebagai sarana silaturahmi agar migran permanen asal Indramayu mudik ke kampung.

Tabel 8. Kegiatan Responden Selama Migrasi.

Table 8. Type of Migrant Activities During Migration.

\begin{tabular}{|c|c|c|c|c|c|c|c|c|}
\hline \multirow{3}{*}{$\begin{array}{l}\text { Tipe Migrasi/ } \\
\text { Type of Migration }\end{array}$} & \multicolumn{8}{|c|}{ Kegiatan Pendatang / Migran Activity } \\
\hline & \multicolumn{2}{|c|}{$\begin{array}{c}\text { Menjual Ikan dan Hasil } \\
\text { Olahan/Selling Fish and } \\
\text { Preserved Product }\end{array}$} & \multicolumn{2}{|c|}{$\begin{array}{c}\text { Berdagang non } \\
\text { Perikanan/ } \\
\text { Non Fishery Trader }\end{array}$} & \multicolumn{2}{|c|}{$\begin{array}{l}\text { Berburuh pada Industri } \\
\text { PengolaharPerikanan/ } \\
\text { Labor in Fish Industry }\end{array}$} & \multicolumn{2}{|c|}{$\begin{array}{l}\text { Menangkap Ikan } \\
\text { Catching Fish }\end{array}$} \\
\hline & $f$ & $\%$ & f & $\%$ & $f$ & $\%$ & $f$ & $\%$ \\
\hline $\begin{array}{l}\text { Migran sirkuler/ } \\
\text { Migrant periodic }\end{array}$ & 26 & 57,8 & 1 & 2,2 & 10 & 22,2 & 4 & 8,9 \\
\hline $\begin{array}{l}\text { Migran permanen/ } \\
\text { Migrant permanen }\end{array}$ & 0 & 0,0 & 0 & 0,0 & 4 & 8,9 & 0 & 0,0 \\
\hline Total/ Total & 26 & $\mathbf{5 7 , 8}$ & 1 & 2,2 & 14 & 31,1 & 4 & 8,9 \\
\hline
\end{tabular}

Sumber: Diolah dari Data Primer (2009)/ Source: Processed from Primary Data (2009) 
Migran yang melakukan migrasi sirkulasi mingguan rata-rata memperoleh pendapatan kotor sekitar Rp. 228.770 per migran. Pendapatan kotor mingguan paling tinggi adalah diperoleh migran Eretan Kulon dengan pendapatan rata-rata Rp. 889 ribu per migran, dan paling rendah berkisar antara Rp. 228 ribu sampai Rp. 258 ribu per migran pada migran dari desa llir dan desa Dadap.

Pada sisi lain rata pendapatan kotor migran sirkulasi bulanan adalah $R p$ 5,4 juta per migran. Pendapatan tertinggi adalah Rp. 11 juta per migran terdapat pada migaran di desa Dadap, sedangkan pendapatan terendah Rp. 1,1 juta per migran terdapat pada migran di Desa Kalibaru Jakarta Utara. Pada sisi lain rata-rata pendapatan kotor migran permanen adalah Rp. 10,8 juta per migran terdapat pada migran di Kalibaru. Tigginya pendapatan migran di Kalibaru merupakan faktor penarik bagi penduduk desa pesisir untuk bermigrasi ke Jakarta.

Rata-rata pendapatan yang dikirim migran sirkulasi mingguan ke daerah asalnya sekitar Rp. 390 ribu per migran. Migran sirkulasi mingguan yang paling banyak mengirim uang ke desa asalnya adalah migran di Desa Eretan Kulon, sedang migran yang paling sedikit mengirimkan uang ke desa asalnya adalah migran dari Desa Dadap. Jumlah uang yang dikirim migran bulanan ke daerah asalnya rata-rata sekitar Rp. 4,3 juta per migran. Migran bulanan yang paling banyak mengirim uang adalah migran dari Desa Dadap (Rp. 10,8 juta per migran), dan yang paling sedikit mengirim uang ke desa asalnya adalah migran dari Kalibaru (Rp. 450 ribu per migran). Sedangkan jumlah uang yang dikirimkan migran permanen dari ke desa asalnya rata-rata Rp. 3,9 juta per migran per bulan.

\section{Penguasaan Aset dan Konsumsi Penguasaan Aset}

Salah satu dampak dari migrasi adalah berkembangnya aset yang dikuasai/dimiliki oleh migran. Terdapat beberapa aset yang dimiliki oleh migran baik yang produktif maupun yang konsumtif. Namun sebagian besar aset yang dimiliki oleh migran masuk dalam kategori aset yang konsumtif. Aset yang paling banyak dimiliki oleh migran adalah ternak, unggas, televisi, kulkas, radio, sepeda, sepeda motor, jaring/alat tangkap ikan, kapal motor, handphone, dan perahu. Aset tersebut diperoleh secara tunai, kredit dan ada pula yang diperoleh dari hibah/warisan. Aset yang mempunyai nilai ekonomi tinggi adalah kapal motor dan jaring dan alat tangkap ikan.

Estimasi total nilai aset dari migran di Kalibaru dan Cilincing masing-masing adalah Rp 26.673.767 dan Rp 1.424.398.333. Aset yang paling mahal adalah kapal penangkap ikan. Nilai aset yang dimiliki migran tersebut dapat menstimulasi pertumbuhan ekonomi di daerah migrasi.

Di daerah asal migrasi aset-aset yang dimiliki meliputi: kulkas, handphone, televisi, sepeda dan sepeda motor, perahu, kapal motor penangkap ikan, jaring alat tangkap ikan, ternak ruminansia kecil dan unggas. Dari keempat desa asal migran tersebut, yang mempunyai nilai aset paling tinggi adalah Desa Eretan Kulon, sebesar Rp 537.867.298 sedangkan nilai aset migran di Desa Dadap Rp 509.985.500, Desa Eretan Wetan Rp 413.816.000 dan Desa Ilir Rp 24.441.250.

Asistensi pengelolaan aset produktif di daerah migrasi ini perlu dijadikan program pembangunan, tujuannya untuk membuka lapangan kerja dan menghimpun dana masyarakat. Asistensi ini diharapkan dapat menjadi bagian dari upaya pengurangan kemiskinan dan mengatasi masalah kerentangan pangan.

\section{Konsumsi}

Terdapat dua kategori konsumsi dalam migrasi ini yaitu: konsumsi pangan dan konsumsi non pangan. Konsumsi pangan merupakan konsumsi migran di daerah tujuan dan daerah asal migran. Terdapat beberapa bahan pangan yang dikonsumsi migran seperti: padi-padian dan tepung, umbi- 
umbian, ikan, telur, susu, sayuran, kacangkacangan, buah-buahan, lemak dan minyak goreng, tembakau, makanan jadi, minuman ringan, bumbu masak dan lainnya. Pengeluaran migran untuk konsumsi pangan sangat bervariasi, di Desa Dadap pengeluaran rata-rata konsumsi per bulan mencapai Rp. 1,4 juta, di Desa Cilincing dan Desa Kalibaru masing-masing sebesar Rp. 845 ribu dan Rp. 652 ribu. Pengeluaran rata-rata untuk konsumsi migran adalah sekitar Rp. 918 ribu perbulan.

Pada sisi lain rata-rata pengeluaran konsumsi non pangan migran mencapai Rp. 1,58 juta per bulan. Pengeluaran non pangan paling tinggi di daerah tujuan migrasi adalah di Desa Cilincing Rp. 3,9 juta per bulan dan paling rendah adalah Rp. 675 ribu per bulan di Desa Kalibaru. Pengeluaran konsumsi non pangan meliputi antara lain: sewa rumah, perawatan rumah, bahan bakar, air minum, listrik, aneka barang dan jasa, biaya kesehatan, biaya pendidikan. Sedangkan di daerah asal migran pengeluaran konsumsi non pangan paling tinggi di Desa Dadap (Rp. 3,2 juta per bulan) dan paling rendah adalah di Eretan Wetan (Rp. 450 juta per bulan). Rata-rata pengeluaran konsumsi non pangan di daerah asal migrasi adalah Rp. 1,6 juta per bulan. Rata-rata total pengeluaran konsumsi migran (pangan dan non pangan) yaitu Rp. 2,5 juta per bulan.

\section{KESIMPULAN DAN IMPLIKASI KEBIJAKAN}

Mobilitas tenaga kerja dari desa pesisir ke daerah tujuan migrasi merupakan kegiatan penting, karena dapat memperoleh pekerjaan dan pendapatan. Migrasi merupakan alternatif rumahtangga di daerah pesisir untuk lepas dari kemiskinan dan kerentanan pangan.

Mobilitas tersebut dipicu oleh faktor pendorong (dari daerah asal) adalah menipisnya potensi sumberdaya ikan di perairan sekitar desa pesisir, terbatasnya akses masyarakat terhadap potensi ekonomi desa, terbatasnya lapangan kerja, dan rendahnya harga hasil tangkapan nelayan. Faktor penarik (dari daerah tujuan migrasi) adalah tersedianya lapangan kerja dengan upah yang pasti.

Secara ekonomi migrasi tersebut memberi dampak positif bagi daerah asal migran dan daerah tujuan migran. Nilai positif dari migrasi adalah terciptanya lapangan kerja baru di desa asal dan memperkuat usaha di daerah tujuan migrasi. Akumulasi aset dan kapital yang dapat medorong pertumbuhan ekonomi, dan menciptakan lapangan kerja di daerah asal migran. Ekspansi usaha di daerah tujuan memerlukan bahan baku dari daerah lain.

Migrasi tenaga kerja ke daerah tujuan migrasi mampu mentransfer uang ke desa asal migran sekitar Rp. 500 juta per bulan. Akumulasi jumlah uang ini perlu dipertimbangkan dalam rancangan pengembangan perekonomian desa pesisir. Migrasi tersebut juga mendorong peningkatan pengeluaran untuk konsumsi pangan dan non pangan pada desa pesisir. Migrasi telah mengungkit perekonomian desa pesisir. Oleh sebab itu, program pemberdayaan masyarakat di desa pesisir perlu menyinergikan uang tersebut dengan dana program sektoral dan CSR yang terdapat di desa pesisir.

\section{DAFTAR PUSTAKA}

Anitawati, M.T. 1986. Analisis Pendapatan Migran dari Desa ke Kota dan Analisa faktor-faktor yang berpengaruh terhadap peluang Migrasi. Tesis. IPB. Bogor.

Bauder, H. 2006. Labor Movement: How Migration Regulates Labor Markets, New York: Oxford University Press.

Clark-Kazak, C. 2008. Power and politics in migration narrative methodology: Research with young Congolese migrants in Uganda. Journal Migration Letters, 6(2). 
Cliggett L and D.L Crooks. 2007. Promoting Multi-methods Research: Linking Anthropometric Methods to Migration Studies, 4(2).

Colter, Y. 1984. Ciri-ciri dan pola tenaga kerja migran dari daerah pedesaan. Rural Dinamic Series. No. 24. Studi Dinamika Pedesaan. Yayasan Penelitian Survey Agro Ekonomi. Bogor.

Dinas Perikanan dan Kelautan. 2009. Laporan Tahunan Dinas Perikanan dan Kelautan Kabupaten Indramayu. Indramayu

Gunawan, M dan Erwidodo. 1992. Urbanisasi Temporer di Jawa Barat. Dinamika Keterkaitan Desa Kota di Jawa Barat: Arus Tenaga Kerja, Barang dan Kapital. Monograph series No. 4. PSE Bogor.

Hutoon,L. 1998. Immigration to Spain: Implication for Unified European Union Immigration Policy. International Migration Review, 32(2).

Moran-Taylor, M.J. 2009. Going North, Coming South: Guatemalan Migratory Flow. Journal Migration Letters, 6(2).

Nielsen, A. 2009. The Algerian wife or "l'amour n'a pas d'age". Migration Letters, 6(6).

Noekman K. M dan Erwidodo. 1992. Migrasi di Pedesaan Jawa. Dinamika Keterkaitan Desa Kota di Jawa Barat: Arus Tenaga Kerja, Barang dan Kapital. Monograph series No. 4. PSE Bogor.

Prabowo, H, Wardoyo, H. Suprapto, 2004. Laporan Penelitian Mandiri Proses Marginalisasi Masyarakat Nelayan Betawi Di Teluk Naga. Universitas Gunadarma, Depok.

Schaefer, M.B. 1957. Some considerations of Population Dynamics and Economics in relation to the Management of Marine Fisheries. Journal of. Fisheries Research Board of Canada. 14.

Soegijoko, BTS. 2005. Pembangunan Kota Indonesia dalam Abad 21: Konsep dan Pendekatan Pembangunan Perkotaan di Indonesia.

Sumodiningrat, G. 2007. Pemberdayaan Sosial: Kajian Ringkas tentang Pembangunan Manusia Indonesia,
Jakarta: Kompas. Hal. 22.

Ullah, AKM , 2004. Bright City Lights and Slums of Dhaka city: Determinants of rural-urban migration in Bangladesh, Journal Migration Letters, 1(1). 
